\title{
Virus-Specific RNA Synthesis in Cells Infected by Infectious Pancreatic Necrosis Virus
}

\author{
PAUL SOMOGYI† AND PETER DOBOS* \\ Department of Microbiology, College of Biological Science, University of Guelph, Guelph, Ontario \\ N1G 2W1, Canada
}

\begin{abstract}
Pulse-labeling experiments with $\left[{ }^{3} \mathrm{H}\right]$ uridine revealed that the rate of infections pancreatic necrosis virus-specific RNA synthesis was maximal at 8 to $10 \mathrm{~h}$ after infection and was completely diminished by 12 to $14 \mathrm{~h}$. Three forms of RNA intermediates were detected: (i) a putative transcription intermediate (TRI) which comigrated in acrylamide gels with virion double-stranded RNA (dsRNA) after RNase treatment; (ii) a 24S genome length mRNA which could be resolved into two bands by polyacrylamide gel electrophoresis; and (iii) a 14S dsRNA component indistinguishable from virion RNA by gradient centrifugation and gel electrophoresis. The TRI (i) was $\mathrm{LiCl}$ precipitable; (ii) sedimented slightly faster and broader (14 to 16S) than the 14S virion dsRNA; (iii) had a lower electrophoretic mobility in acrylamide gels than dsRNA, barely entering acrylamide gels as a heterogenous component; (iv) yielded genome-sized pieces of dsRNA after RNase digestion; and ( $v$ ) was the most abundant RNA form early in the infectious cycle. The 24S single-stranded RNA was thought to be the viral mRNA since it: (i) became labeled during short pulses; (ii) was found in the polysomal fraction of infected cells; and (iii) hybridized to denatured viral RNA, forming two segments of RNase-resistant RNA that comigrated with virion dsRNA in gels. The 24S mRNA component was formed before the synthesis of dsRNA, and radioactivity could be chased from $24 \mathrm{~S}$ single-stranded RNA to dsRNA, indicating that 24S RNA may serve as template for the synthesis of complementary strands to form dsRNA. Similar to reovirus, infectious pancreatic necrosis viral $24 \mathrm{~S}$ mRNA contained no polyadenylic acid tracts.
\end{abstract}

The genome of infectious pancreatic necrosis virus (IPNV) consists of two pieces of high-molecular-weight, double-stranded RNA (dsRNA) $\left(2.5 \times 10^{6}\right.$ and $\left.2.3 \times 10^{6}\right)$ that sedimented as an RNase-resistant $14 \mathrm{~S}$ component in sucrose gradients $(5,12)$. Upon denaturation, the sedimentation constant increased to $24 \mathrm{~S}$ and the RNA became sensitive to RNase (5). The electron microscopic diameter of IPNV was found to be $59 \mathrm{~nm}$, and the virion had a sedimentation coefficient of 435S (7). The virion contains four proteins representing the products of three genes: one large (molecular weight, 90,000), one medium (molecular weight, 57,000), and two small proteins (molecular weight, 29,000 and 28,000 ); the latter two are related, as shown by peptide mapping (8). Another protein (molecular weight, 27,000) is the product of a fourth gene and is only present in the infected cell (8).

The question arose: How can two segments of dsRNA mediate the synthesis of four unrelated proteins? Four possibilities were considered: (i) transcription of genome length mRNA followed

† Present address: Microbiological Research Group, Hungarian Academy of Sciences, 1529 Budapest, Hungary. by posttranslational cleavage of large precursor protein(s); (ii) transcription of subgenomic, monocistronic mRNA pieces; (iii) transcription of genome length mRNA with subsequent cleavage to functional mRNA pieces, or (iv) transcription of genome length mRNA having multiple initiation and termination sites for translation. Since recent experiments have shown no evidence for large precursor polypeptides in IPNV-infected cells $(6,8)$, we attempted to distinguish between the other possibilities by analyzing the size and number of virus-specific mRNA species in infected cells. Our results showed that there were three forms of intracellular virus specific RNAs: (i) a putative transcription intermediate (TRI) which barely entered $2 \%$ acrylamide gels and was partially RNase sensitive; (ii) a singlestranded RNA (ssRNA) species of about 24S that migrated as two components between the 28S and 18S rRNA markers in acrylamide gels and was associated with polysomes; and (iii) two pieces of dsRNA that comigrated with the bisegmented virus genome in acrylamide gels. Of particular interest was the fact that no subgenomic size mRNA's were found in virus-infected 
cells. These results suggest that IPNV synthesizes two genome length mRNA transcripts that are translated into four different proteins by a mechanism that may not involve posttranslational cleavage of precursor polypeptides.

(Portions of these results were presented at the Annual Meeting of the American Society for Microbiology in Los Angeles [Abstr. Annu. Meet. Am. Soc. Microbiol. 1979, S134, p. 262]).

\section{MATERIALS AND METHODS}

Cells. Chinook salmon embryo cells (CHSE-214) were a kind gift from R. D. Macdonald, University of Calgary, Calgary, Canada. The cells were grown at $22^{\circ} \mathrm{C}$ as monolayers in plastic culture flasks (Corning Plastics, Inc.) with Eagle minimum essential medium (MEM) with Earles salts, supplemented with $10 \%$ fetal calf serum (FCS) and penicillin (100 IU/ $\mu \mathrm{l})$ and streptomycin $(100 \mu \mathrm{g} / \mathrm{ml})$.

Virus. The Jasper strain of IPNV was used in this investigation since it gave high titers and did not generate defective interfering particles even during multiple, undiluted passages (13). To grow stock virus, cell monolayers were infected at a multiplicity of 0.1 and incubated at $20^{\circ} \mathrm{C}$, and virus was harvested when gross cytopathogenic effect was evident, usually 2 to 3 days later. The infectious titer was determined by plaque assay as described previously (6), and the virus was dispensed in small portions and stored at $-70^{\circ} \mathrm{C}$.

Growth and purification of $\left[{ }^{3} \mathrm{H}\right]$ uridine-labeled virus. CHSE cell monolayers were infected with undiluted virus for $1 \mathrm{~h}$ at $20^{\circ} \mathrm{C}$. The virus inoculum was replaced with fresh MEM containing $1 \%$ FCS and 0.5 $\mu \mathrm{g}$ of actinomycin D (Act-D) per ml. The volume of this medium was reduced so that it would just cover the monolayer. After a 2 -h incubation at $20^{\circ} \mathrm{C},\left[{ }^{3} \mathrm{H}\right]-$ uridine was added $(10 \mu \mathrm{Ci} / \mathrm{ml})$, and the cultures were further incubated until extensive cytopathic effect was evident. The virus was concentrated by polyethylene glycol precipitation and purified by freon extraction and alternate cycles of sucrose gradient centrifugation and $\mathrm{CsCl}$ isopynic density gradient centrifugation as described before (8).

$\left[{ }^{3} \mathrm{H}\right]$ uridine labeling and extraction of intracellular RNA. Multiple cultures of CHSE cells (in 75- $\mathrm{cm}^{2}$ Corning flasks) were infected with undiluted stock virus for $1 \mathrm{~h}$ at $20^{\circ} \mathrm{C}$. The virus inoculum was replaced with MEM containing $0.5 \mu \mathrm{g}$ of Act-D per ml, and incubation continued at $20^{\circ} \mathrm{C}$. At various times after infection, cultures were withdrawn, and the MEM was replaced with $7 \mathrm{ml}$ of MEM which contained 1\% FCS, $0.5 \mu \mathrm{g}$ of Act-D per ml, and $15 \mu \mathrm{Ci}$ of $\left[{ }^{3} \mathrm{H}\right]$ uridine per $\mathrm{ml}$. The cultures were further incubated at $20^{\circ} \mathrm{C}$ for various times, depending on the length of the radioactive pulse (usually $2 \mathrm{~h}$ ), at which time the medium was removed, the monolayers were rinsed, and the cells were lysed in $1.5 \mathrm{ml}$ of lysing buffer $(0.05 \mathrm{M}$ Tris [pH 7.5], $0.1 \mathrm{M} \mathrm{NaCl}, 4 \mathrm{mM}$ EDTA, 1\% EDTA, 1\% sodium dodecyl sulfate [SDS], $1 \%$, 1,5-napthalene-disulfonic acid, disodium salt, and $1 \mathrm{mg}$ of proteinase $\mathrm{K}$ per $\mathrm{ml}$ ). The preparation was incubated at $37^{\circ} \mathrm{C}$ overnight to allow the proteinase $\mathrm{K}$ to digest the cellular proteins and release the RNA. This protease treatment was especially necessary to release dsRNA from progeny virions, since it has been shown before (14) that it is difficult and very inefficient to extract IPNV dsRNA by phenol alone. The preparation was passed through a Bio-Gel P30 column, prepared in a 5-ml pipette, to remove small molecules such as proteinase K, tRNA, and small labeled oligonucleotides. The RNA was extracted three times with freshly distilled phenol mixed with chloroform (1:1). The residual phenol was removed from the aqueous phase by ether extraction, and the ether was in turn removed by bubbling $\mathrm{N}_{2}$ through the preparation. One-tenth volume of $2.5 \mathrm{M}$ ammonium acetate was added, and the RNA was precipitated at $-20^{\circ} \mathrm{C}$ after the addition of two volumes of cold absolute ethanol.

Lithium chloride precipitation. The alcohol-precipitated RNA was washed three times with $70 \%$ ethanol and then resuspended in autoclaved TNE buffer $(0.01 \mathrm{M}$ Tris, $0.1 \mathrm{M} \mathrm{NaCl}, 1 \mathrm{mM}$ EDTA, $\mathrm{pH}$ 7.5). An equal volume of cold, sterile $4 \mathrm{M} \mathrm{LiCl}$ solution was added, and the RNA was precipitated at $4^{\circ} \mathrm{C}$ overnight. The preparation was centrifuged in the cold at $10,000 \mathrm{rpm}$ for $30 \mathrm{~min}$, and the supernatant, containing LiCl-soluble dsRNA, was removed. The precipitate again was dissolved in TNE buffer, made $2 \mathrm{M}$ with respect to $\mathrm{LiCl}$, and reprecipitated in the cold overnight as described above. This procedure was repeated three times. The $\mathrm{LiCl}$-soluble fractions, after two more cycles of salt precipitation, were pooled; the LiCl-insoluble RNA was dissolved in TNE buffer; and both preparations were precipitated with ethanol at $-20^{\circ} \mathrm{C}$. For further studies, RNA was removed from alcohol by centrifugation and was resuspended in the appropriate buffer.

Sucrose gradient centrifugation. Both RNA preparations ( $\mathrm{LiCl}$ soluble and insoluble) were resuspended in $0.2 \mathrm{ml}$ of TNE buffer containing 1\% SDS (TNES) layered onto 5 to $20 \%$ linear sucrose gradients prepared in the same buffer. Rate zonal centrifugation was performed at $40,000 \mathrm{rpm}$ at $22^{\circ} \mathrm{C}$ for $3 \mathrm{~h}$ in an SW50.1 rotor by using a Beckman L2-65B preparative ultracentrifuge. The gradients were fractionated by piercing the bottom of the centrifuge tubes. Portions $(100 \mu \mathrm{l})$ from each fraction were applied to glass fiber filters (Whatman GF1A), and after drying they were placed in cold $10 \%$ trichloracetic acid at $4^{\circ} \mathrm{C}$ for 30 $\mathrm{min}$. The filter disks were washed in ice-cold methanol and dried. The acid-precipitable radioactivity was counted in a liquid scintillation counter with a toluenebased scintillation cocktail $[0.4 \%(w t / v o l)$ PPO (2,5diphenyloxazole) and $0.01 \%$ (wt/vol) POPOP [1,4-bis(5-phenoloxazolyl)-benzene].

Unlabeled 28S and 18S rRNA was centrifuged in parallel tubes and was located in the gradients by measuring the optical density at $260 \mathrm{~nm}$ of gradient fractions.

RNAse digestion. RNA samples were tested for RNase sensitivity in $2 \times$ SSC (SSC: $0.15 \mathrm{M} \mathrm{NaCl}, 0.015$ $\mathrm{M}$ sodium citrate, $\mathrm{pH} 7.4)$ with $2 \mu \mathrm{g}$ of pancreatic RNase A per $\mathrm{ml}$ at room temperature for $30 \mathrm{~min}$.

Preparation of polysomes from pulse-labeled cells. Polysomes were prepared as described by Wiegers and Hilz (20). The final preparation was dissolved in lysing buffer and incubated for $2 \mathrm{~h}$ at $37^{\circ} \mathrm{C}$ to allow the proteinase $\mathrm{K}$ to digest all proteins. The RNA was then subjected to sucrose gradient centrifugation as described above. 
Radioactive labeling of infected cells for polyacrylamide gel electrophoresis. CHSE cells were grown in flat-bottomed, multiwell Linbro trays (24 wells per tray). Confluent monolayers were infected with undiluted stock IPNV at $20^{\circ} \mathrm{C}$ for $1 \mathrm{~h}$. The inoculum was removed, and the cells were overlaid with MEM $(0.4 \mathrm{ml} /$ well) containing $1 \% \mathrm{FCS}$ and 0.5 $\mu \mathrm{g}$ of Act-D per $\mathrm{ml}$. At various times after infection, $0.1 \mathrm{ml}$ of $\left[{ }^{3} \mathrm{H}\right]$ uridine in balanced salt solution was added to each well to a final concentration of $10 \mu \mathrm{Ci} /$ $\mathrm{ml}$. At the end of the labeling period, the medium was removed and the monolayers were dissolved in $0.1 \mathrm{ml}$ of electrophoretic sample buffer, lysing buffer containing 5\% sucrose and a trace of bromophenol blue. The cell lysates were forced through a narrow-gauge needle to shear the DNA, dispensed into 0.5-ml-capacity microtubes (Beckman, polyethylene), and were allowed to stand at room temperature overnight for the proteinase $\mathrm{K}$ digestion. Samples $(10 \mu \mathrm{l})$ were spotted onto glass fiber filters to determine the trichloroacetic acidprecipitable radioactivity. The preparation was then stored at $-70^{\circ} \mathrm{C}$ until gel electrophoresis.

For pulse-chase experiments, the medium containing $\left[{ }^{3} \mathrm{H}\right]$ uridine was removed from the cells and replaced with MEM ( $2 \mathrm{ml} /$ well) containing an excess of unlabeled uridine. At various times after the chase period, the medium from each well was centrifuged $\left(40,000 \mathrm{rpm}, 1 \mathrm{~h}, 4^{\circ} \mathrm{C}\right.$, with the SW50.1 rotor) to pellet extracellular virus. The monolayer was dissolved in electrophoretic sample buffer, and this was added to dissolve the pellet before incubation and storing.

Polyacrylamide gel electrophoresis. The RNA samples were analyzed on composite agarose-acrylamide slab gels by the method of Sinclair and Mindish (17), followed by fluorography as described by Bonner and Laskey (1).

Purified, labeled virion dsRNA was sometimes run for comparison. In this case the purified virus pellet was treated with electrophoretic sample buffer overnight at room temperature to allow the proteinase $K$ to release the RNA. Thereafter the sample was kept frozen until used. Heating to $70^{\circ} \mathrm{C}$ before electrophoresis was omitted for virion RNA.

Unlabeled virion dsRNA was also analyzed in 5\% acrylamide gels, followed by staining with ethidium bromide, as described previously (5).

Viral proteins were analyzed in $10 \%$ discontinuous SDS-slab gels, as described before (8).

RNA-RNA hybridization. Samples containing radioactive $24 \mathrm{~S}$ ssRNA, 0.2 to 0.3 absorbance units at $260 \mathrm{~nm}$ of unlabeled virion dsRNA, and $1 \mu \mathrm{mol}$ of EDTA (pH 7.2) in a total volume of $100 \mu \mathrm{l}$ were heated for $90 \mathrm{~s}$ at $100^{\circ} \mathrm{C}$ and then incubated at $50^{\circ} \mathrm{C}$ for $2 \mathrm{~h}$ to allow annealing. After incubation, $0.1 \mathrm{ml}$ of $0.6 \mathrm{M}$ $\mathrm{NaCl}$ and $60 \mathrm{mM}$ sodium citrate containing $2 \mu \mathrm{g}$ of RNase were added, and the samples were incubated at room temperature for $30 \mathrm{~min}$. Carrier tRNA was added, and the RNA was precipitated with 2 volumes of cold ethanol. The alcohol precipitates were resuspended in electrophoretic sample and analyzed on composite agarose-acrylamide gels.

Oligo(dT)-cellulose chromatography. Oligodeoxythymidylic acid [oligo(dT)]-cellulose $(0.1 \mathrm{~g})$ was suspended in autoclaved binding buffer $(0.5 \mathrm{M} \mathrm{NaCl}$, $0.5 \%$ SDS, $0.01 \mathrm{M}$ Tris-hydrochloride, $\mathrm{pH} \mathrm{7.4)}$ and layered over a 5-mm glass wool column and 5-mm cellulose powder column in a sterile $1-\mathrm{ml}$ plastic syringe. The column was extensively washed with binding buffer, after which the labeled RNA in binding buffer was layered on the top of the column. Fractions $(0.2 \mathrm{ml})$ were collected until background levels of radioactivity were attained. Bound RNA was then recovered by washing the column with elution buffer (0.05\% SDS, $0.01 \mathrm{M}$ Tris-hydrochloride, $\mathrm{pH}$ 7.4). ${ }^{3} \mathrm{H}$ labeled 18S rRNA and ${ }^{3} \mathrm{H}$-labeled encephalomyocarditis (EMC) virus RNA were used as controls.

Materials. FCS, MEM, and antibiotics were purchased from Gibco Laboratories. Recrystallized acrylamide, bisacrylamide, and $N, N, N^{\prime}, N^{\prime \prime}$-tetramethylenediamine and Bio-Gel P30 were obtained from BioRad Laboratories. SDS (specially pure) and proteinase $\mathrm{K}$ were obtained from British Drug Houses. [5,6${ }^{3} \mathrm{H}$ ] uridine (specific activity, 40 to $50 \mathrm{Ci} / \mathrm{mol}$ ), PPO, and POPOP were purchased from New England $\mathrm{Nu}$ clear Corp. Oligo(dT)-cellulose was obtained from Collaborative Research Inc., and RNase A was from Sigma Chemical Co.

\section{RESULTS}

Genome and proteins of IPNV. The RNA and polypeptide composition of purified IPNV is shown in Fig. 1. If the virion proteins were the translation products of monocistronic viral mRNA's, one would expect to find intracellular mRNA's with molecular weights of approximately $0.9 \times 10^{6}, 0.6 \times 10^{6}$, and $0.3 \times 10^{6}$ which could code for the three size classes of virion polypeptides. Based upon the molecular weights of the genome dsRNA's, genome length mRNA's should be approximately $1.25 \times 10^{6}$ and $1.15 \times$ $10^{6}$ daltons.

RNA synthesis in Act-D-treated, infected, and uninfected cells. Act-D was used to inhibit host cell RNA synthesis. Preliminary experiments showed that the presence of Act- $D$ at a concentration of $0.5 \mu \mathrm{g} / \mathrm{ml}$ reduced the yield of progeny virus by $0.5 \mathrm{log}$ at most, yet it inhibited host cell RNA synthesis by 80 to $90 \%$ within 3 to $4 \mathrm{~h}$ after addition. Therefore, virus-specific RNA could be labeled preferentially by addition of $\left[{ }^{3} \mathrm{H}\right]$ uridine to infected cultures 3 to $4 \mathrm{~h}$ after the addition of Act-D. The data in Fig. 2 show the effect of Act-D on the synthesis of total RNA in uninfected and IPNV-infected cells. When infected cells were pulse-labeled for $2 \mathrm{~h}$ at 2-h intervals from 2 to $12 \mathrm{~h}$ after infection, the amount of RNA synthesized increased up to 8 to $10 \mathrm{~h}$, followed by a rapid decrease, reaching negligible levels by 12 to $14 \mathrm{~h}$.

Pattern of RNA synthesis in virus-infected cells. It was of interest to determine the types of RNA synthesized in virus-infected cells under conditions in which host cell RNA synthesis was depressed by Act-D. To this end, Act$\mathrm{D}(0.5 \mu \mathrm{g} / \mathrm{ml})$ was added to infected and mockinfected cultures after virus adsorption (zero time), and $2 \mathrm{~h}$ later the cultures were pulse- 


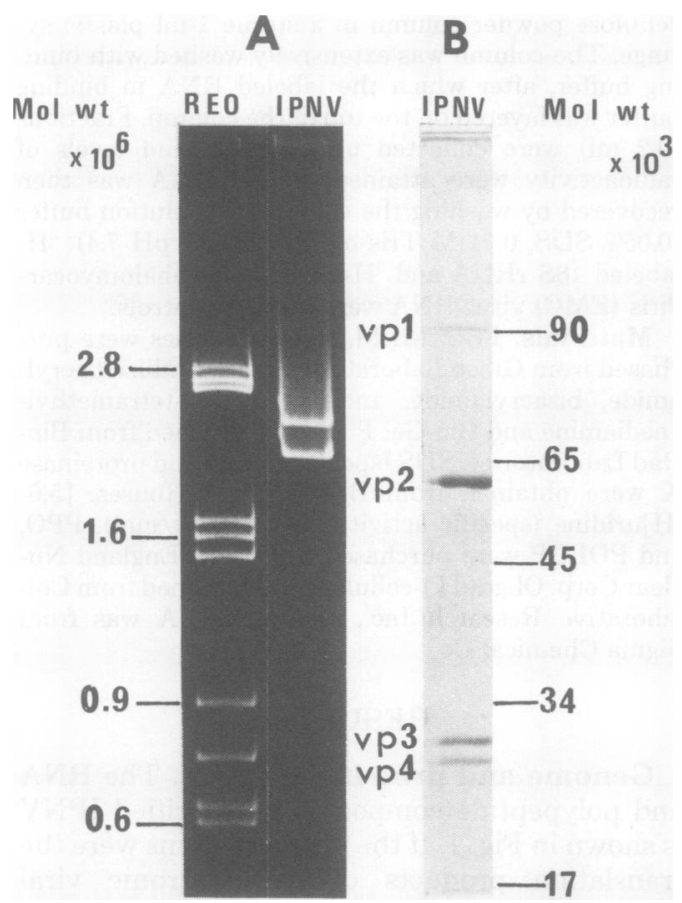

Fig. 1. Virion RNA and proteins of IPNV. (A) Polyacrylamide gel electrophoresis of IPNV RNA together with reovirus RNA (type 3 Dearing) in 5\% acrylamide gels followed by staining with ethidium bromide. (B) Polyacrylamide gel electrophoresis of proteins of purified IPNV in 10\% discontinuous SDSgel. The gels were stained with Coomassie brilliant blue. The position and the molecular weight $\times 10^{3}$ of the marker proteins are shown on the right, and that of the virion proteins is shown on the left. The marker proteins used were phosphorylase $A(90,000)$, bovine serum albumin $(65,000)$, ovalbumin $(45,000)$, aspartate transcarbamylase $(34,000)$, and tobacco mosaic virus protein $(17,000)$.

labeled with $\left[{ }^{3} \mathrm{H}\right]$ uridine for $2 \mathrm{~h}$ at 2 -h intervals from 2 to $12 \mathrm{~h}$ after infection. The cell lysates were analyzed for RNA by acrylamide gel electrophoresis and fluorography. The results in Fig. 3 show that IPNV-specific RNA species were synthesized in infected cells by 2 to $4 \mathrm{~h}$ after infection.

The earliest form of viral RNA detected in these gels was an RNA species which could be resolved into two components and migrated in the gels between the 28S and 18S rRNA markers. This RNA was called 24S RNA (see Fig. 4 below) and was the predominant form of RNA. The amount of 24S RNA synthesized at various times after infection (as judged from the intensity of bands) paralleled the accumulation of virus-specific RNA shown in Fig. 2. The synthesis of 24S RNA was detectable in the 2- to 4- $\mathrm{h}$ pulse; however, its presence was unambiguous after $4 \mathrm{~h}$.

A second form of virus-specific RNA which was discernible in the fluorogram was an RNA that comigrated with the double-stranded viral genomic RNA segments. This RNA appeared later than the 24S RNA and could be labeled in infected cells between 6 and $12 \mathrm{~h}$ after infection.

A third form of virus-specific RNA was a heterogenous RNA species of low electrophoretic mobility that barely entered the $2 \%$ acrylamide gel. We named this RNA form TRI instead of replicative intermediate (RI) because this RNA was present at the same time as $24 \mathrm{~S}$ RNA but before the synthesis of progeny dsRNA. This RNA was often obscured (as in Fig. 3) because: (i) there was a substantial amount of radioactivity at the origin of the gel; (ii) there was a nonspecific band (marked $\mathrm{X}$ ) present even in the uninfected cell lysates. This nonspecific band was also present when sucrose gradient-purified $28 \mathrm{~S}$ or $18 \mathrm{~S}$ labeled rRNA was analyzed in these gels (Fig. 4). Since we used [5$\left.{ }^{3} \mathrm{H}\right]$ uridine, it was highly unlikely that the nonspecific band would represent DNA, such as mitochondrial DNA. The amount of RNA trapped in this region also depended on the amount of material loaded onto the gel. In some cases there was little radioactivity left at the origin, and the nonspecific band was absent, yet

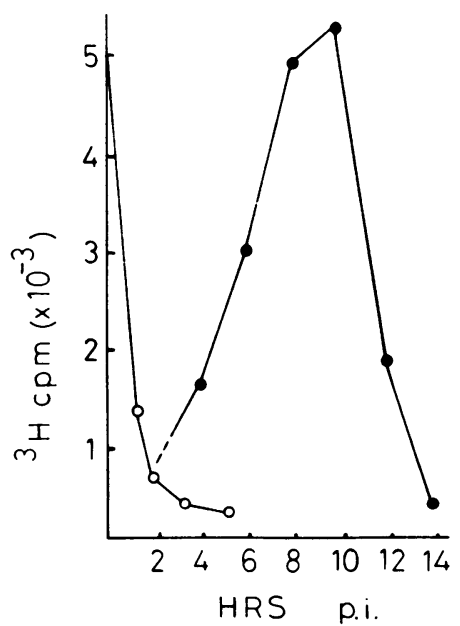

FiG. 2. RNA synthesis in Act-D-treated uninfected and infected cells. IPNV-infected and mock-infected CHSE cells were pulse-labeled for $2 h$ at 120-min intervals from 2 to $12 \mathrm{~h}$ after infection with $\left.{ }^{3} \mathrm{H}\right]$ uridine. The monolayers were dissolved in electrophoretic sample buffer, and the trichloroacetic acidprecipitable radioactivity was determined as described in the test. Symbols: $O$, Uninfected cells; 0 , infected cells. 


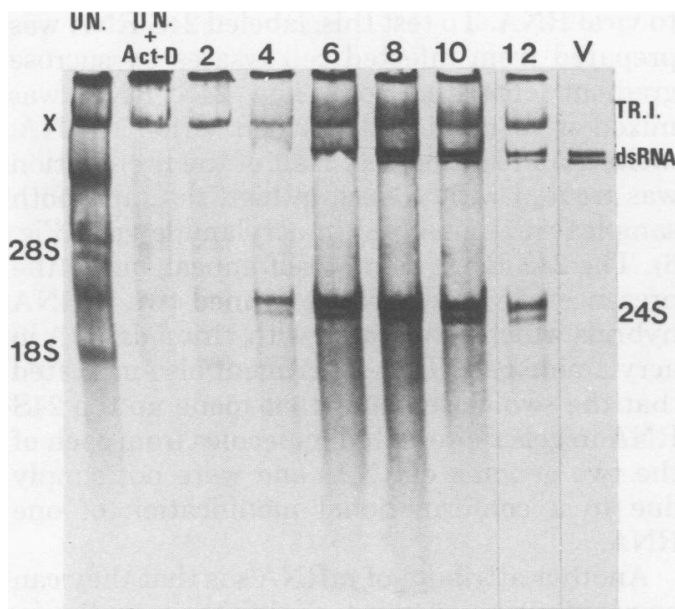

Fig. 3. Time course of RNA synthesis in IPNV. infected, Act-D-treated CHSE cells. Mock-and virusinfected cell monolayers were treated with Act-D $(0.5$ $\mu \mathrm{g} / \mathrm{ml}$ ) from 0 to $2 \mathrm{~h}$ after infection followed by pulselabeling with $\left[{ }^{3} H\right]$ uridine for $2 h$ at $2-h$ intervals from 2 to $12 \mathrm{~h}$ after infection. The monolayers were dissolved in electrophoretic sample buffer, and heated to $70^{\circ} \mathrm{C}$, and the $R N A$ was analyzed by electrophoresis in $2 \%$ acrylamide-agarose slab gels followed by fluorography. Labeled virion dsRNA was also included for comparison. The numbers above the wells indicate the time (after infection) when the isotope was added. The position of $28 \mathrm{~S}$ and $18 \mathrm{~S}$ rRNA is shown on the left. The position of TRI, virion dsRNA, and $24 S$ virus-specific RNA is shown on the right. The location of the nonspecific band described in the text is marked with $X$.

the TRI could clearly be observed (Fig. 4D).

Further evidence for a TRI. dsRNA is soluble in $2 \mathrm{M} \mathrm{LiCl}$, whereas ssRNA and transcription complexes containing single-stranded nascent chains (such as the TRI) are precipitated by $\mathrm{LiCl}$ and can be subsequently separated from each other by sucrose gradient centrifugation or acrylamide gel electrophoresis. To investigate the nature of 24S RNA and the TRI, phenolextracted RNA from labeled, infected cells was separated into $\mathrm{LiCl}$-soluble and $\mathrm{LiCl}$-precipitable fractions by repeated cycles of precipitation and analyzed on sucrose gradients as described in Materials and Methods. The majority of $\mathrm{LiCl}$ precipitable RNA sedimented between the two rRNA markers as a $24 \mathrm{~S}$ component (Fig. 5A). A minor peak sedimented behind the 18S rRNA as a 14 to $16 \mathrm{~S}$ component. Samples from fractions 11 to 29 were subjected to acrylamide slab gel electrophoresis and fluorography as shown in Fig. 5B. The RNA in the $24 \mathrm{~S}$ peak had a high electrophoretic mobility and migrated in the gel between the RNA markers. The 14 to 16S RNA showed low electrophoretic mobility and was heterogenous in nature, two characteristics of transcription intermediates. Note that the 14 to 16S RNA (TRI) sedimented on sucrose close to the genome 14S dsRNA but migrated slower in acrylamide gels than the dsRNA. Sucrose gradient fractions representing the $24 \mathrm{~S}$ and 14 to $16 \mathrm{~S}$ peaks were pooled separately, and the amount of acid-precipitable radioactivity was determined before and after RNase treatment. The data in Table 1 show that the 24S RNA was completely sensitive to RNase, whereas about $14 \%$ of the 14 to $16 \mathrm{~S}$ RNA was resistant to RNase, and this resistant RNA comigrated with virion dsRNA in the acrylamide gel shown in Fig. 5B (lane $A$ ).

24S RNA is viral mRNA. The size and

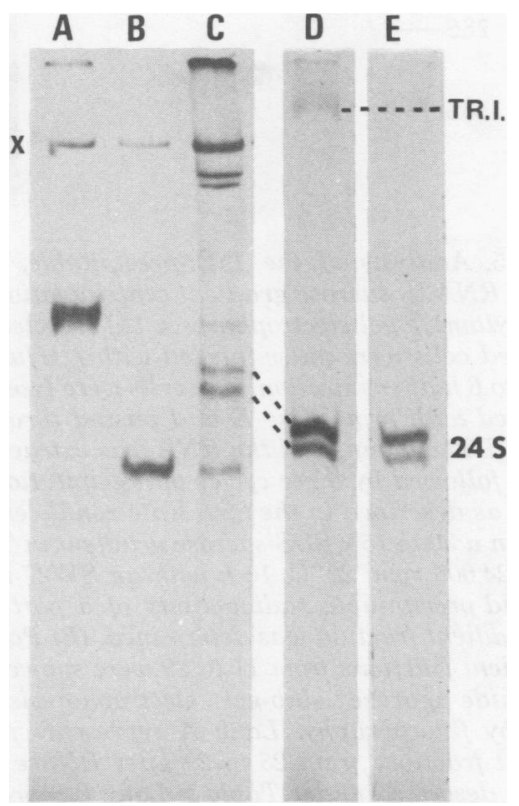

Fig. 4. Analysis of cellular and virus-specific RNAs in $2 \%$ acrylamide-agarose gel followed by fluorography. Lanes $A$ and $B$ show the electrophoretic pattern of labeled, phenol-extracted rRNA which has been purified by sucrose gradient centrifugation before gel electrophoresis. Lane A, 28S rRNA; lane B, $18 S$ rRNA. Nonspecific band marked with $X$. Lane $C$ shows an autoradiogram when rRNA, 24S RNA, and viral dsRNA are run in the same well. Lane $D$ demonstrates the TRI without the nonspecific band. Here infected Act-D-treated cells were pulse-labeled with $\left.{ }^{3} \mathrm{H}\right]$ uridine from 6 to $7 \mathrm{~h}$ after infection; the cells were lysed in electrophoretic sample buffer, heated to $70^{\circ} \mathrm{C}$ for $2 \mathrm{~min}$, and subjected to gel electrophoresis and fluorography. Lane $E$ shows the fluorogram of labeled RNA present in the polysomal fraction of infected Act-D-treated cells. Samples of lane $D$ and $E$ were electrophoresed on a different gel than those of $A, B$, and $C$; thus, the position of $24 S R N A$ does not coincide in the two sets (see dashed line). 


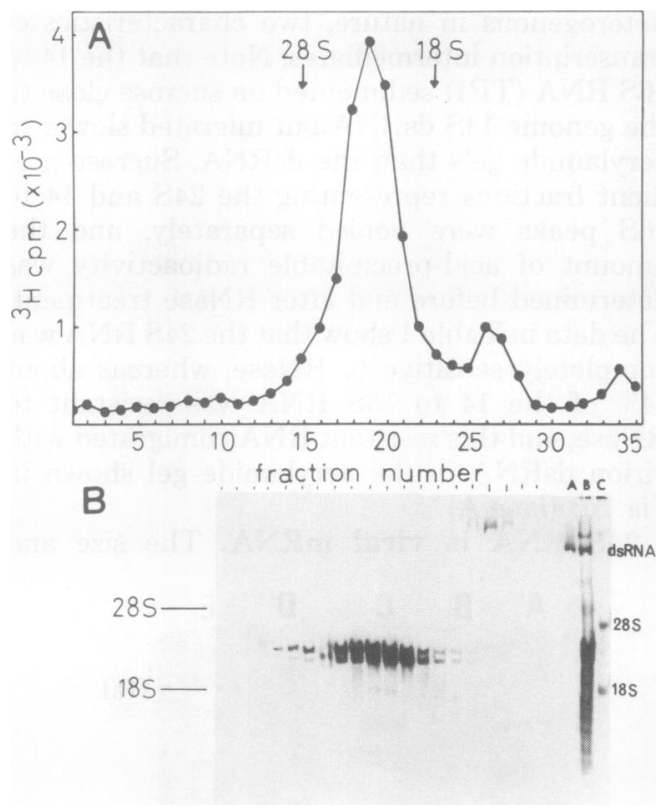

Fig. 5. Analysis of the LiCl-precipitable, virusspecific RNA by sucrose gradient centrifugation and polyacrylamide gel electrophoresis. (A) Infected Act$D$-treated cells were pulse-labeled with $\left[{ }^{3} H\right]$ uridine from 5 to $6 \mathrm{~h}$ after infection. The cells were lysed and incubated with proteinase $K$ and passed through a Bio-Gel P30 column, and the RNA was extracted by phenol, followed by three cycles of precipitation of 2 $M \mathrm{LiCl}$ as described in the text. Rate zonal centrifugation in a 30 to $15 \%$ SDS-sucrose gradient in TNES buffer $\left(24,000 \mathrm{rpm}, 22^{\circ} \mathrm{C}, 16 \mathrm{~h}\right.$ with an $S W 27$ rotor). The acid-precipitable radioactivity of a portion of each gradient fraction was determined. (B) Portions of gradient fractions from 11 to 29 were subjected to acrylamide-agarose slab-gel electrophoresis, followed by fluorography. Lane $A$ represents pooled gradient fractions from 25 to 29 after RNase treatment as described under Table 1. Lane $B$ represents total virus specific RNA from cells labeled from 6 to $8 \mathrm{~h}$ after infection. Lane $C$ shows $28 \mathrm{~S}$ and $18 \mathrm{~S}$ rRNA markers.

RNase sensitivity of the 24S RNA indicated that it was a genome length transcript of the viral RNA and that it most likely represented viral mRNA. To further investigate this possibility, infected cell extracts were prepared with Nonidet P-40 and Dounce homogenization, and the postmitochondrial fraction was pelleted by ultracentrifugation $(140,000 \times g, 2 \mathrm{~h})$. The resulting polysomal pellet was treated with proteinase $\mathrm{K}$ and subjected to acrylamide gel electrophoresis. The predominant, labeled RNA was the 24S RNA as shown in Fig. 4E.

If the 24S polysomal RNA was viral mRNA representing "plus" strands of the doublestranded viral genome, then it should hybridize to viral RNA. To test this, labeled 24S RNA was prepared from infected cell lysates by sucrose gradient centrifugation. The 24S RNA was mixed with unlabeled purified virion dsRNA, melted, and reannealed. Half of the preparation was treated with RNase in high salt, and both samples were analyzed in acrylamide gels (Fig. 6). The 24S RNA did not self-anneal, but in the presence of virion RNA it formed two dsRNA hybrids which comigrated with virion dsRNA in acrylamide gels. This experiment also indicated that the two close bands that made up the 24S RNA in gels represented molecules from each of the two genome dsRNAs and were not simply due to a conformational modification of one RNA.

Another attribute of mRNA's is that they can be rapidly labeled when, during their synthesis, cells are incubated with RNA precursors for a short time. When virus-infected cells were labeled with $\left[{ }^{3} \mathrm{H}\right]$ uridine for 15 or $30 \mathrm{~min}$ at $6 \mathrm{~h}$ after infection, only the 24S RNA became labeled, as shown in Fig. 9. Taken together, these experiments indicate that the 24S RNA represents viral mRNA.

Kinetics of virus-specific RNA synthesis. Although acrylamide gel electrophoresis was a useful method for qualitative analysis of the types of virus-specific RNA synthesized in infected cells, it was unreliable for quantitative studies due to the variable amount of radioactivity left on top of the gel and to the presence of the nonspecific band $(\mathrm{X})$ in all preparations. Denaturing gels were not used because they may have denatured the dsRNA. For this reason, the time course of synthesis of the three forms of virus-specific RNAs (24S, TRI, and dsRNA) was

TABLE 1. RNase sensitivity of three forms of virusspecific $R N A s$

\begin{tabular}{lcc}
\hline RNA form & $\begin{array}{c}\text { Acid-precipitable } \\
\text { cpm }\end{array}$ & $\begin{array}{c}\text { \% RNase re- } \\
\text { sistance }\end{array}$ \\
\hline 24S $^{a}$ & 32,000 & 1 \\
TRI (14-15S) $^{b}$ & 6,200 & 14 \\
dsRNA (14S) & 8,000 & 92 \\
\hline
\end{tabular}

${ }^{a}$ 24S RNA represents gradient fractions from 11 to 23 in Fig. 5, and TRI represents fractions 25 to 29 from the same gradients. The representative fractions were pooled, precipitated with ethanol, and resuspended in $0.2 \mathrm{ml}$ of $2 \times \mathrm{SSC}$. Half of each preparation was treated with RNase A (5 $\mu \mathrm{g} / \mathrm{ml}, 30 \mathrm{~min}$ at room temperature), and the acid-precipitable radioactivity of untreated and RNase-treated samples were determined as described in the text.

${ }^{b}$ Labeled virion dsRNA was released from purified virus by proteinase $K$ treatment. It was separated from the protease by phenol extraction and alcohol precipitation; RNase treatment was carried out as described for 24S RNA and TRI. 


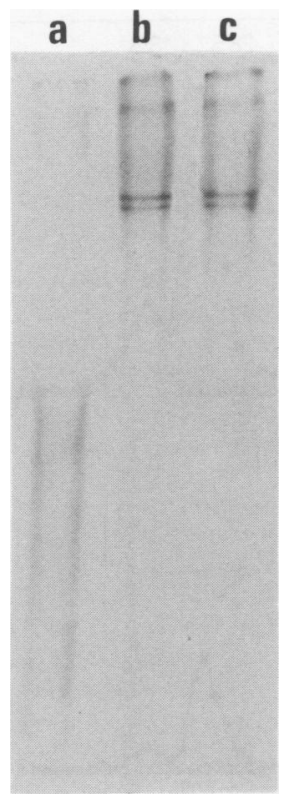

Fig. 6. Hybridization of labeled 24S RNA to unlabeled virion dsRNA. Purified $\left[{ }^{3}\right.$ H] uridine-labeled 24S RNA and unlabeled virion RNA in $1 \mu \mathrm{mol}$ of EDTA (pH 7.2) were heated for $90 \mathrm{~s}$ at $100^{\circ} \mathrm{C}$ and then incubated at $50^{\circ} \mathrm{C}$ for $2 \mathrm{~h}$ to allow annealing. The salt concentration was adjusted to that of $2 \times$ SSC, and half of the sample was treated with RNase $(2 \mu \mathrm{g} / \mathrm{ml}, 30 \mathrm{~min}$ at room temperature). Lane a, $24 \mathrm{~S}$ RNA self-annealing followed by RNase treatment; lane $b,{ }^{3} \mathrm{H}$-labeled $24 S \mathrm{RNA}$ annealed to unlabeled virion RNA; lane c, ${ }^{3} \mathrm{H}$-labeled $24 S \mathrm{RNA}$ annealed to virion RNA followed by RNase treatment.

analyzed by sucrose gradient centrifugation of LiCl-soluble and LiCl-precipitable RNA pulselabeled with $\left[{ }^{3} \mathrm{H}\right]$ uridine. Cell extracts were passed through a column of Bio-Gel P30 to remove small molecules such as peptides, proteinase $\mathrm{K}, \mathrm{tRNA}$, and unincorporated $\left[{ }^{3} \mathrm{H}\right]$ uridine. The samples were phenol extracted, alcohol precipitated, and separated by three cycles of $\mathrm{LiCl}$ precipitation. Both $\mathrm{LiCl}$-soluble and LiCl-insoluble RNAs were precipitated with ethanol, and the precipitates were resuspended in TNES buffer, followed by sucrose gradient centrifugation in 5 to $20 \%$ sucrose gradients in TNES buffer $\left(40,000 \mathrm{rpm}\right.$ at $22^{\circ} \mathrm{C}$ for $3 \mathrm{~h}$ in an SW50.1 rotor). The gradient RNA profiles of the three forms of RNA at different times after infection are shown in Fig. 7.

Between 2 to $4 \mathrm{~h}$ after infection, only the $24 \mathrm{~S}$ mRNA and the 14 to $16 \mathrm{~S}$ TRI became labeled. Between 4 to $6 \mathrm{~h}$ the 24S mRNA was the predominant species, although a small amount of $14 \mathrm{~S} \mathrm{LiCl}$-soluble (dsRNA) was also detectable. The synthesis of $24 \mathrm{~S}$ mRNA reached its peak between 8 and $10 \mathrm{~h}$ after infection and declined thereafter. The kinetics of synthesis of the TRI roughly paralleled that of the $24 \mathrm{~S}$ mRNA. The synthesis of the 14S dsRNA reached its peak at 8 to $10 \mathrm{~h}$ after infection, and although it slowly declined thereafter (due perhaps to virion release), its contribution to the total labeled RNA increased so that between 12 to $14 \mathrm{~h}$, almost half of the labeled RNA was double-stranded.

When the radioactivity represented by three peaks was summed at each time interval, a composite graph was plotted to show the amount of each of the three RNA forms present relative to each other and to that of the total RNA (Fig. 8). A numerical presentation of the precent contribution of each RNA to the total is shown in Table 2.

24S mRNA may be the precursor for progeny dsRNA. The synthesis of $24 \mathrm{~S}$ mRNA preceded that of progeny dsRNA, as shown in Fig. 3 and 7. In reovirus-infected cells, the "minus" strands of viral RNA are made on plusstrand templates to yield progeny dsRNA (22). We attempted to see whether this was also the case in IPNV-infected cells by pulse-labeling 24S mRNA with $\left[{ }^{3} \mathrm{H}\right]$ uridine and then chasing it with excess unlabeled uridine. The data in Fig. 9 show that when infected cells were pulse-labeled for 15,30 , and $60 \mathrm{~min}$ at $7 \mathrm{~h}$ after infection, the 24S mRNA became labeled but the dsRNA was not labeled (dsRNA became labeled only if 2-h or longer pulses were used as shown in Fig. 3 ). When infected cells were pulse-labeled with $\left[{ }^{3} \mathrm{H}\right]$ uridine for $30 \mathrm{~min}$ and chased for a 6- or 12$h$ period, the amount of radioactivity decreased in the 24S mRNA component and increased in the dsRNA. These data are compatible with (but do not prove) the hypothesis that the complementary strands of the dsRNA are synthesized asynchronously, possibly via singlestranded plus RNA intermediates. Furthermore, the fact that intracellular dsRNA cannot be labeled by short pulses suggests that, like reovirus, IPNV RNA replicates by a conservative mechanism.

The drawback of this type of experiment is the long period of chase required before radioactivity can be demonstrated in putative product molecules (in this case, dsRNA). This is due to the presence of large intracellular uridine pools which cannot be diluted out except over long periods of time. Therefore, the data shown in Fig. 9 can also be interpreted in a manner that does not imply a precursor-product relationship between mRNA and dsRNA (see Discussion). However, the results of hybridization experiments make a "reovirus-like" mechanism a more likely possibility.

24S mRNA contains no poly(A) tracks. The mRNA's of all animal viruses so far studied 


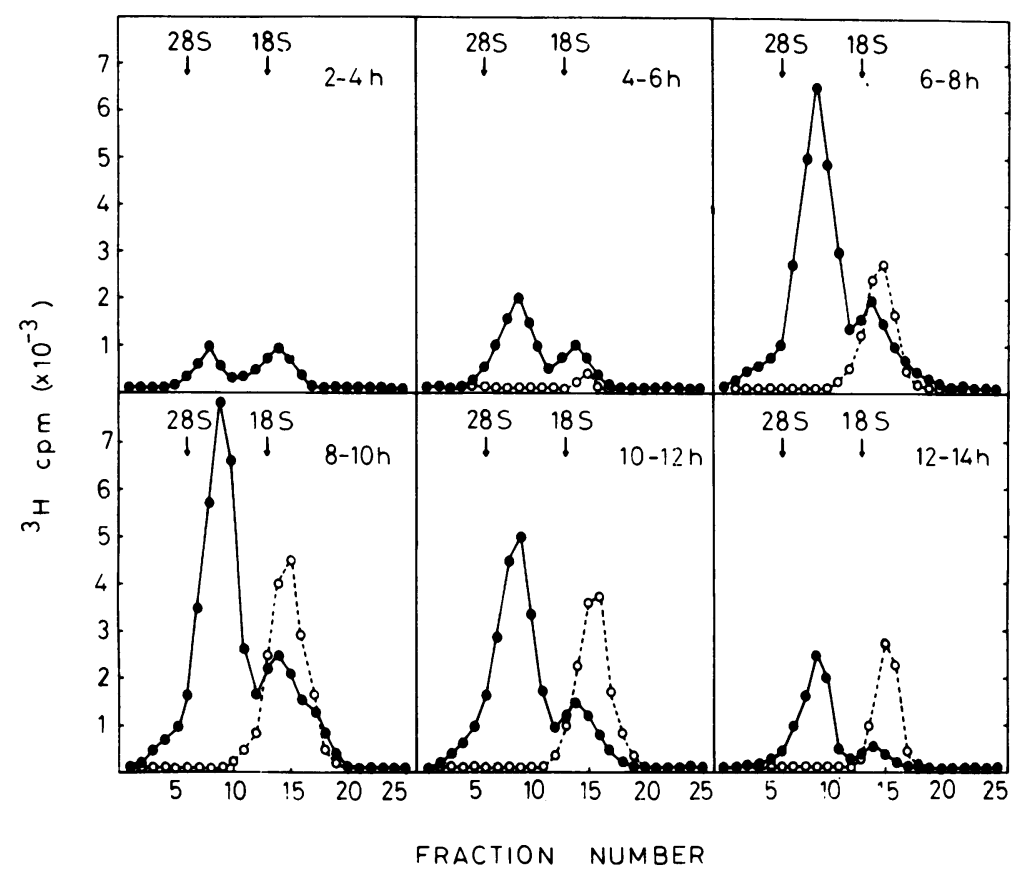

Fig. 7. Time course of LiCl-precipitable and LiCl-soluble RNA synthesis in IPNV-infected CHSE cells as determined by pulse-labeling with $\left[{ }^{3} H\right]$ uridine followed by sucrose gradient centrifugation. Cultures were labeled for $2 \mathrm{~h}$ at 120-min intervals from 2 to $12 \mathrm{~h}$ after infection, and the RNA was extracted as described in the legend of Fig. 5. The LiCl-soluble $\left(\mathrm{O}_{-}-\mathrm{O}_{\text {) }}\right.$ and $\mathrm{LiCl}$-precipitable (-O) preparations were analyzed by rate zonal centrifugation in 5 to $20 \%$ SDS-sucrose gradients.

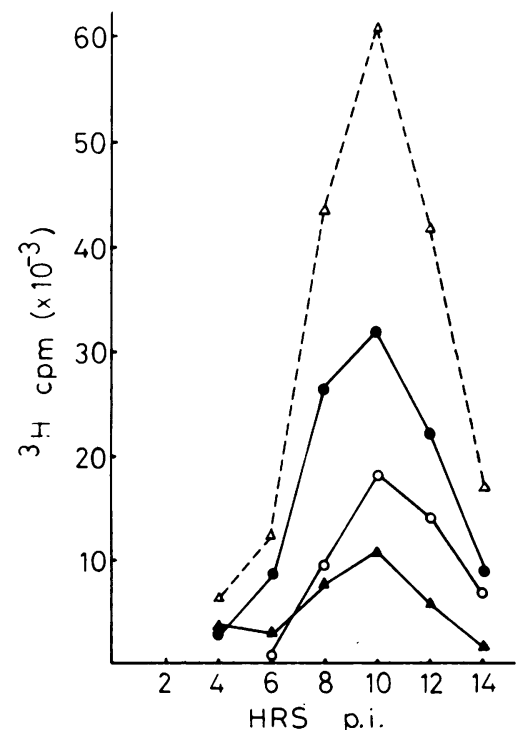

FIG. 8. Synthesis of the three forms of virus-specific RNA in infected cells. At each time interval, the amount of radioactivity present in the gradient fractions under each peak in Fig. 7 was summed and plotted with respect to time $(\Delta---\Delta)$ total $R N A$; (O-O) $24 S$ mRNA ( $\mathrm{LiCl}$-precipitable); (O-O) 14S dsRNA ( $\mathrm{LiCl}$ soluble); ( (LiCl precipitable).
TABLE 2. Temporal synthesis of IPNV RNA intermediates after infection ${ }^{a}$

\begin{tabular}{ccccc}
\hline \multirow{2}{*}{$\begin{array}{c}\text { Time of } \\
\text { pulse (h) }\end{array}$} & $\begin{array}{c}\text { Total RNA } \\
\text { (cpm) }\end{array}$ & \multicolumn{3}{c}{ \% of total RNA } \\
\cline { 3 - 5 } & & TRI & mRNA & dsRNA \\
\hline $2-4$ & 6,400 & 55 & 45 & 0 \\
$4-6$ & 12,100 & 25 & 69 & 6 \\
$6-8$ & 43,850 & 22 & 60 & 18 \\
$8-10$ & 60,950 & 18 & 53 & 29 \\
$10-12$ & 41,700 & 13 & 53 & 35 \\
$12-14$ & 17,250 & 8 & 51 & 41 \\
\hline
\end{tabular}

${ }^{a}$ The amount of radioactivity represented by each peak in Fig. 7 was expressed as the percentage of total radioactivity found in each gradient.

except reovirus contain a polyadenylic acid [poly(A)] tract of variable length at the $3^{\prime}$ end of the RNA (18). The length of the poly(A) tracts ranges from 15 nucleotides as in EMC virus RNA (2) to about 200 nucleotides as in Rous sarcoma virus RNA (4).

To determine whether IPNV 24S mRNA contained poly(A), we have subjected $\left[{ }^{3} \mathrm{H}\right]$ uridinelabeled purified 24S mRNA to chromatography on oligo(dT)-cellulose. Labeled 18S rRNA served as negative control and labeled purified EMC RNA was used as positive control. The data in Fig. 10 show that under conditions in 


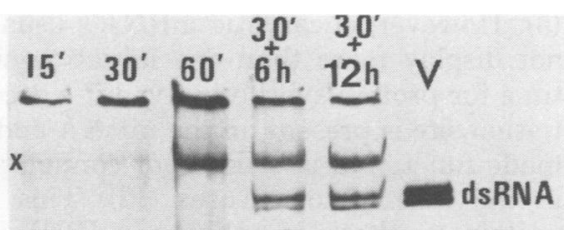

24S

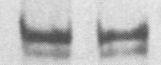

Fig. 9. Possible precursor-product relationship between 24S mRNA and viral dsRNA. Infected, Act$D$-treated cells were pulse-labeled for 15, 30, and 60 min with $\left[{ }^{3} \mathrm{H}\right]$ uridine $7 \mathrm{~h}$ after infection. The radioactivity was "chased", in two cultures that had been pulse-labeled for 30 min, by incubation for 6 and 12 $h$ in the presence of excess unlabeled uridine. The lysed cells were subjected to acrylamide-agarose gel electrophoresis followed by fluorography, together with purified, labeled viral dsRNA. The position of the nonspecific band is marked with $X$.

which $86 \%$ of EMC RNA was bound to the oligo(dT)-cellulose, both IPNV 24S mRNA and 18S rRNA could be eluted from the column. Since EMC RNA contains a short poly(A) stretch of only 14 to 18 nucleotide residues long, even such a short poly(A) tract on IPNV $24 \mathrm{~S}$ mRNA would have been detected.

\section{DISCUSSION}

Animal viruses with dsRNA genomes such as reovirus replicate via ssRNA intermediates which serve as templates for the synthesis of their complementary strands (11). These ssRNA intermediates in reovirus-infected cells are called plus strands because they also function as mRNA. Evidence that the two segments of $24 \mathrm{~S}$ ssRNA described in this paper are viral RNAs and are probably intermediates in the replication of IPNV dsRNA includes the following: (i) they are found only in infected cells and are labeled in the presence of Act-D; (ii) they can be "chased into dsRNA"; (iii) they have sedimentation properties that are identical to that of denatured virion dsRNA (5); and (iv) they hybridize with virion dsRNA. The 24S ssRNA's may function as mRNA's since both species can be rapidly labeled by short pulses and both can be isolated from the polysomal fraction of in- fected cells. Similar to reovirus, the IPNV mRNA contains no poly (A) tracts.

The properties of IPNV TRI are similar to those reported by Franklin (9) for the RI of phage R17: (i) it sediments slightly faster than dsRNA; (ii) it has a lower electrophoretic mobility in acrylamide gels than dsRNA; in fact, it barely enters $2 \%$ gels; (iii) it precipitates in $2 \mathrm{M}$ $\mathrm{LiCl}$; and (iv) it yields genome-sized pieces of dsRNA after RNase digestion. These data are consistent with a structure composed of a fulllength dsRNA molecule and one or more partially completed ssRNA transcripts. Although the RI of the R17 phage exists as a singlestranded complex that anneals upon deproteinization (19), it is unlikely that this is the case with IPNV since it has a dsRNA genome. The TRI of IPNV makes up most of the intracellular virus-specific RNAs during the early part of the infectious cycle (Table 2) when there is a rapid increase in the rate of synthesis of $24 \mathrm{~S} \mathrm{mRNA.}$ Although no TRI (or RI) have been reported in reovirus-infected cells per se, these kinds of molecules would be found in parental and progeny subviral particles which synthesize mRNA on dsRNA templates using the ds $\rightarrow$ ssRNA polymerase(s) (27). Since reovirus transcribes plus strands in a conservative manner (16), rapid labeling of progeny dsRNA does not occur because the complementary strands are synthesized at different times. Our results indicate that a similar mechanism is operating in IPNV be-

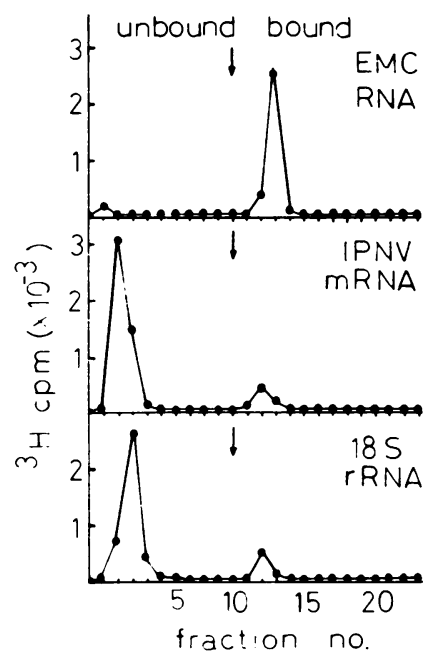

Fig. 10. Chromatography of $\left[{ }^{3} \mathrm{H}\right]$ uridine-labeled, IPNV-specific 24S mRNA, EMC virus RNA, and $18 S$ $r R N A$ on oligo(dT)-cellulose. The RNAs in binding buffer were added to the column and washed with the same buffer until 10 fractions were collected. Then the eluant was changed to elution buffer to displace the bound RNA. 
cause: (i) dsRNA becomes labeled only when pulses of $2 \mathrm{~h}$ (or longer) are used; (ii) radioactivity could be chased from $24 \mathrm{~S}$ mRNA into dsRNA; and (iii) 24S mRNA hybridized with denatured viral dsRNA.

The most likely reason why dsRNA cannot be labeled by short pulses is because only a small minority of molecules are replicating at any one time and are not detected until longer times elapsed. The data in Fig. 9 show that a major problem in the examination of RNA synthesis in animal cells is the difficulty in following the fate of RNA that has been synthesized and labeled during a short exposure or pulse to radioactive RNA precursors. This is because the large intracellular pools of RNA precursors cannot be diluted out or emptied except over long periods of time. For this reason, 24S mRNA was still being labeled during the 6-h chase, and to a much smaller extent even during the 12-h chase period. Nevertheless, radioactivity could be chased, albeit slowly, from 24S mRNA to dsRNA.

Alternatively, the data shown in Fig. 9 are also compatible with the theory that dsRNA became labeled during the 6-h chase (but not during the $30-\mathrm{min}$ pulse), merely because the rate of synthesis of dsRNA was slower than that of 24S mRNA. Hence, even the "slowly made" dsRNA became labeled during the 6-h chase, which could be regarded as a long (6-h) pulse because of the large intracellular labeled uridine pool. Indeed the amount of label in $24 \mathrm{~S}$ mRNA increased during this period compared with the sample that represents the $30-\mathrm{min}$ pulse. It may also be argued that the loss of label from 24S mRNA after a 12-h chase was due to RNA breakdown rather than to movement of mRNA into dsRNA, especially since the amount of label increased but little in the dsRNA region after this additional 6-h chase period.

It would be highly desirable to be able to firmly establish the mechanism of IPNV dsRNA synthesis by the elegant method of Schonberg et al. (16) who showed unequivocally that the complementary strands of reovirus genome were synthesized asynchronously. Unfortunately, this experiment requires large amounts of unlabeled plus strands which can be produced readily in vitro, by using reovirus cores; however, repeated attempts to synthesize IPNV mRNA in vitro in our laboratory have so far been unsuccessful.

During the course of this investigation, we have not detected any subgenomic-sized mRNA in IPNV-infected cells; therefore, the relationship between the virus-specific proteins and the virus genome still remains to be determined. One possibility is that the 24S mRNA's have multiple initiation and termination signals for translation similar to the mRNA of RNA phages
(3). However, eucaryotic mRNA's usually cannot display more than one initiation site at a time for protein synthesis, even if a second initiation site is present on the mRNA and can be made functional in a different configuration as in the case of togaviruses (12). This kind of protein synthesis is unlikely in IPNV-infected cells, for we have shown previously that all three size classes of virus-specific polypeptides are produced throughout the replicative cycle (6). Of course, farfetched as it may seem, it is possible that in the IPNV mRNA population each of the four initiation sites for the four different proteins are represented on different mRNA's by secondary folding right from the beginning of the infection. A second possibility is that IPNV mRNA is functionally similar to that of Kunjin virus (member of flaviviruses) which contain multiple internal initiation sites for translation of virusspecific proteins as shown by Westaway (21). Poliovirus RNA may also have two initiation sites for protein synthesis (10). A third possibility is that VP1 is the primary gene product of one of the genome segments, and the mediumand small-size IPNV polypeptides (VP2, VP3, and the nonstructural polypeptide of $27,000 \mathrm{mo}-$ lecular weight) are produced by rapid posttranslational cleavage from a polyprotein, the latter being the primary gene product of the other genome segment. As reported previously, we have failed to detect polyprotein precursor(s) in IPNV-infected cells with amino acid analogs, protease inhibitors, $\mathrm{ZnCl}_{2}$, supraoptimal temperatures, and pulse-chase experiments $(6,8)$. It should be noted, however, that sometimes these conventional techniques to demonstrate precursor-product relationships are not sufficient. For example, the existence of a precursor polypeptide for Sindbis virus structural proteins was demonstrated convincingly only with the use of temperature-sensitive mutants which failed to exhibit proteolytic cleavage at the nonpermissive temperature (15).

Whichever of these possibilities turns out to be true, the results so far show that the mechanism of virus-specific RNA synthesis in IPNVinfected cells is similar to that of reovirus, but virion proteins are produced from IPNV mRNA's by a different mechanism than that found in reovirus-infected cells.

\section{ACKNOWLEDGMENTS}

We thank R. Macdonald for his helpful criticism during the preparation of this manuscript.

This investigation was supported by the National Research Council of Canada.

\section{LITERATURE CITED}

1. Bonner, W. M., and R. A. Laskey. 1974. A film detection method for tritium labeled proteins and nucleic acids in 
polyacrylamide gels. Eur. J. Biochem. 46:83-88.

2. Burness, A. T. H., I. V. Pardoe, E. M. Duffy, R. B. Bhalla, and N. O. Goldstein. 1977. The size and location of the poly(A) tract in EMC virus RNA. J. Gen. Virol. 34:331-345.

3. Cancedda, R., L. Villa-Komaroff, H. F. Lodish, and M. Schlesinger. 1975. Initiation sites for translation of Sindbis virus $42 \mathrm{~S}$ and $26 \mathrm{~S}$ messenger RNAs. Cell 6: 215-222.

4. Coffin, J. M., and M. A. Billeter. 1976. A physical map of the Rous sarcoma virus genome. J. Mol. Biol. 100: 293-318.

5. Dobos, P. 1976. Size and structure of the genome of infectious pancreatic necrosis virus. Nucleic Acid Res. 3:1903-1924.

6. Dobos, P. 1977. Virus-specific protein synthesis in cells infected by infectious pancreatic necrosis virus. J. Virol. 21:242-258.

7. Dobos, P., R. Hallett, D. T. Kells, O. Sorensen, and D. Rowe. 1977. Biophysical studies of infectious pancreatic necrosis virus. J. Virol. 22:150-159.

8. Dobos, $P_{\text {., }}$ and D. Rowe. 1977. Peptide map comparison of infectious pancreatic necrosis virus-specific proteins. J. Virol. 24:805-820.

9. Franklin, R. M. 1966. Purification and properties of the replicative intermediate of the RNA bacteriophage R17. Proc. Natl. Acad. Sci. U.S.A. 55:1504-1511.

10. Jense, H., F. Knauert, and E. Ehrenfeld. 1978. Two initiation sites for translation of poliovirus RNA in vitro: comparison of LSc and Mahoney strains. J. Virol. 28:387-394.

11. Joklik, W. K. 1974. Reproduction of Reoviridae, p. 231334. In H. Fraenkel-Conrat and R. R. Wagner (ed.), Comprehensive virology, vol. 2. Plenum Publishing Co., New York.

12. Kennedy, S. I. T. 1976. Sequence relationship between the genome and the intracellular RNA species of standard defective-interfering Semliki forest virus. J. Mol. Biol. 108:491-551.

13. Macdonald, R. D. 1978. Ringed plaque formation in infectious pancreatic necrosis virus correlates with defecting interfering particle production. J. Gen. Virol. 41: 623-628.

14. Macdonald, R. D., and T. Yamamoto. 1977. The structure of infectious pancreatic necrosis virus RNA. J. Gen. Virol. 34:235-247.

15. Schlesinger, M. J., and S. Schlesinger. 1973. Largemolecular-weight precursors of Sindbis virus proteins J. Virol. 11:1013-1016.

16. Schonberg, M., S. C. Silverstein, D. H. Levin, and G. Acs. 1971. Asynchronous synthesis of the complementary strands of the reovirus genome. Proc. Natl. Acad. Sci. U.S.A. 68:505-508.

17. Sinclair, J. F., and L. Mindich. 1976. RNA synthesis during infection with bacteriophage $\phi 6$. Virology 75: 209-217.

18. Stoltzfus, C. M., A. J. Shatkin, and A. K. Banerjee. 1973. Absence of poladenylic acid from reovirus messenger ribonucleic acid. J. Biol. Chem. 248:7993-7998.

19. Tach, S. S., and R. E. Tach. 1973. Mechanism of viral replication. I. Structure of replication complexes of R17 bacteriophage. J. Mol. Biol. 81:367-380.

20. Weigers, V., and H. Hilz. 1972. Rapid isolation of undergraded polysomal RNA without phenol. FEBS Lett. 23:77-82.

21. Westaway, E. G. 1977. Strategy of the flavivirus genome: evidence for multiple internal initiation of translation of proteins specified by Kunjin virus. Virology 80:320335 .

22. Zweerink, H. J., Y. Ito, and T. Matsuhisa. 1972. Synthesis of reovirus double stranded RNA within viruslike particles. Virology 50:349-358. 